\title{
Exclusive breastfeeding status of children aged between 6 and 24 months in the nomadic population of Hadaleala district, Afar Region, northeast Ethiopia
}

\author{
Zemichael Gizaw ${ }^{1 *}$, Wondwoson Woldu ${ }^{2}$ and Bikes Destaw Bitew ${ }^{1}$
}

\begin{abstract}
Background: Exclusive breastfeeding (EBF) during infancy is fundamental, however it is not fully practiced in the nomadic population of Ethiopia. In Ethiopia, there is still a lack of information on the implementation of the EBF, especially among the nomadic population. This study was conducted to assess the EBF status of children during their first 6 months of life, who are now aged between 6 and 24 months, in the nomadic population of Afar region. The study also aimed to identify factors affecting exclusive breastfeeding.

Methods: A community based cross-sectional study was conducted from April to May, 2015 to assess EBF of children aged between 6 and 24 months during the first 6 months of life. Exclusive breastfeeding is defined as consuming only breast milk (including expressed breast milk) during the first 6 months and no other liquids and solid foods except medications, and non exclusive breastfeeding is taking liquids and solid foods in addition to breast milk. The cluster sampling technique was used to select the study participants. Data were collected from 254 households using a structured questionnaire.

Results: One hundred eighty eight of the children were fed breast milk exclusively for the first 6 months of age; the rate of EBF in the study area was $74 \%$ (95\% Cl 70, 78\%). One hundred fifty four (60.6\%) of the children received breast milk within $1 \mathrm{~h}$ immediately after birth and 207 (81.5\%) of the children maintained breastfeeding at the time of the survey. Exclusive breastfeeding was statistically associated with mothers aged above 35 years (AOR 8.3, 95\% Cl 1.7, 40.3) , commencing to breastfeed in first hour (AOR 3.5, 95\% Cl 1.8,6.9), and parents who didn't migrate or move to a more comfortable area (AOR 4.6, 95\% Cl 1.5, 14.4).

(Continued on next page)
\end{abstract}

\footnotetext{
* Correspondence: zemichael12@gmail.com

${ }^{1}$ Department of Environmental and Occupational Health and Safety, Institute

of Public Health, College of Medicine and Health Sciences, University of

Gondar, Gondar, Ethiopia

Full list of author information is available at the end of the article
} 
(Continued from previous page)

Conclusion: Exclusive breastfeeding was not fully practiced in the study area. Therefore, promotion of infant and young children feeding (IYCF) is needed in the area to strengthen EBF practices. Moreover, child feeding practices should be integrated with the existing health system and attention should be given to the nomadic mothers.

Keywords: Exclusive breastfeeding, Breastfeeding, Breastfed in first hour, Hadaleala district

\section{Background}

Breastfeeding provides an ideal food for the healthy growth and development of infants. As a global public health recommendation, infants should be exclusively breastfed for the first 6 months of life to achieve optimal growth, development and health [1, 2]. Although the benefit of exclusive breastfeeding is widely advocated globally, the rate remains low. Globally, only $40 \%$ of infants aged 6 months or less are exclusively breastfed [3], and in Ethiopia, the rate of EBF is low at 52\% [4]. Ethiopian mothers practice non EBF due to different factors, such as sociodemographic [5-9], healthcare services [5-7, 9-11], and behavioral factors $[6,12-14]$. While, the Ethiopian government is promoting the importance of EBF, there is still a gap with the implementation, especially among the nomadic communities. There is a lack of information on the status of EBF practices among the nomadic population. This study was conducted to assess the EBF status of children during the first 6 months of life, now aged between 6 and 24 months, in the nomadic population of Afar region. The study also aimed to identify factors associated with EBF practices.

\section{Methods}

\section{Study design and settings}

A community based cross-sectional study was conducted in Hadaleala district. Hadaleala district is one of the districts of Afar Regional State, which is located at $341 \mathrm{~km}$ southwest of the regional capital, Semera, and $268 \mathrm{~km}$ north of Addis Ababa, the capital city of Ethiopia. The area of 491.12 mile $^{2}$ is divided into 11 rural kebeles (the smallest administration unit in Ethiopia) with a total population of 42,845 . It has 7516 households with an average household size of 5.7 persons per house. In the district, the proportion of children aged under- 5 years accounts for $10.1 \%$ (4328). The district is about 670 $1280 \mathrm{~m}$ above sea level. The annual mean temperature of the district is 30 degree Celsius, and the district has a very variable precipitation between 440 and $760 \mathrm{~mm}$ annual average. Resources, like pasture and water are dispersed in the district. Due to this, the populations who live in the district are nomadic [15].

\section{Sample size determination and selection of study participants}

The sample size was determined using the single population proportion formula by considering the following assumptions: $p=81 \%$ (the level of EBF among children aged less than 6 months in Amhara region) [16], 95\% confidence interval, and a $5 \%$ margin of error (d),

$$
n=\frac{\left(\mathrm{z}_{\alpha / 2}\right)^{2} p(1-p)}{d^{2}}=\frac{(1.96)^{2} 0.81(1-0.81)}{0.05^{2}}=237
$$

Considering a $5 \%$ non response rate, the final sample size was 249 mother-child pair.

Due to population heterogeneity across the kebeles, a cluster sampling technique was used to select the study participants. The clusters were villages with defined geographical boundaries. Six rural kebeles out of eleven were selected by the simple random sampling technique. The six targeted rural kebeles were clustered into thirtynine villages, and seventeen villages were selected by the systematic random sampling technique. Finally, all the households who have children aged between 6 and 24 months were visited and a total of 258 study participants were included in the study.

\section{Outcome variable of the study}

The primary outcome variable of this study was defined as an infant who was fed only breast milk (including expressed breast milk) during the first 6 months with no other liquids and solid foods except medications, and non exclusive breastfeeding defined as an infant who was fed liquids and solid foods in addition to breast milk [2, 17].

\section{Data collection tools and procedures}

A structured questionnaire was used to collect data. The questionnaire was adapted from similar published studies [18-23] with little modification and translated to Afarigna which is the local language. To validate the adopted questionnaire, a pretest was done on children having similar characteristics with the study participants in different areas who were not part of the study. Any necessary correction was done by considering the characteristics of the participants, study settings, and other contexts. The questionnaire consists of sociodemographic and breastfeeding information. Ten diploma graduate nurses who fluently speak the local language and were working in the district were 
involved in the data collection process. After training on data collection, enumerators visited all the households found in the selected villages. The data collectors interviewed the mothers when they found the targeted children and ascertained the period of exclusive breastfeeding by asking the mothers when they first introduced any solid, semi-solid, or fluid to their child in addition to breast milk, in the first 6 months. For a few mothers who faced difficulties in remembering the right time of initiation of additional foods, data collectors carried out different probing mechanisms to help them to recall. Relating the time of initiation to known public events, occurrence of common childhood developmental milestones, and immunization schedules were some of the probing techniques. There was close supervision to improve the quality of the data.

\section{Data management and statistical analysis}

Data were entered using Epi-Info version 3.5.3 statistical package and exported to SPSS version 20 for further analysis. Descriptive analysis, such as frequency, percentage or proportion, median, and interquartile ranges was conducted for most variables. Univariable binary logistic regression analysis was used to choose variables for the multivariable logistic regression analysis on the basis of $p$-value less than 0.2 . Variables which had a $p$-value less than 0.2 by the univariable analysis were further analyzed by the multivariable binary logistic regression for controlling the possible effects of confounders. Statistically significant variables were identified on the basis of Adjusted Odds Ratio (AOR) with 95\% Confidence Interval $(\mathrm{CI})$ and $p<0.05$.

\section{Results}

Sociodemographic information of children and mothers

A total of 254 mother-child pairs participated in the current study with $98.5 \%$ response rate. Half $(n=131$, $51.6 \%)$ of the mothers were aged between 25 and 34 years. The median age of the mothers was 27 years, and the interquartile range (IQR) was $24-33$ years. Almost all, 250 (98.4\%) of the mothers were married at the time of the survey, and the majority 241 (94.9\%) were housewives by occupation. Two hundred twenty (86.6\%) of the mothers and $226(89.0 \%)$ of the fathers didn't attend any formal education at the time of the survey. More than half, 139 (54.7\%) of the households had a maximum of five families. Of the 254 children included in this study, 133 (52.4\%) were male and 158 (62.2\%) were aged between 13 and 24 months; the median age was 15 months with an interquartile range (IQR) of 11 to 19 months. Forty-four (17.3\%) of the children were first by their birth order, and only $31(12.2 \%)$ of the mothers gave birth in health institutions. Nearly onethird, 82 (32.3\%) of the households moved from place to
Table 1 Sociodemographic information about children aged between 6 and 24 months and their mothers $(n=254)$ in Hadaleala district, Afar Region, northeast Ethiopia

\begin{tabular}{|c|c|c|}
\hline Sociodemographic variables & Frequency & Percent \\
\hline \multicolumn{3}{|l|}{ Age of mothe (years) } \\
\hline $15.0-24.0$ & 79 & 31.1 \\
\hline $25.0-34.0$ & 131 & 51.6 \\
\hline$\geq 35.0$ & 44 & 17.3 \\
\hline \multicolumn{3}{|l|}{ Mothers' marital status } \\
\hline Currently married & 250 & 98.4 \\
\hline Not currently married & 4 & 1.6 \\
\hline \multicolumn{3}{|l|}{ Maternal education } \\
\hline No formal education & 220 & 86.6 \\
\hline Formal education & 34 & 13.4 \\
\hline \multicolumn{3}{|l|}{ Maternal occupation } \\
\hline Not employed & 241 & 94.9 \\
\hline Employed & 13 & 5.1 \\
\hline \multicolumn{3}{|l|}{ Paternal education } \\
\hline No formal education & 226 & 89.0 \\
\hline Formal education & 28 & 11.0 \\
\hline \multicolumn{3}{|l|}{ Family size } \\
\hline$\leq 5$ & 139 & 54.7 \\
\hline$>5$ & 115 & 45.3 \\
\hline \multicolumn{3}{|l|}{ Age of children in months } \\
\hline 6-12 months & 96 & 37.8 \\
\hline 13-24 months & 158 & 62.2 \\
\hline \multicolumn{3}{|l|}{ Sex of children } \\
\hline Male & 133 & 52.4 \\
\hline Female & 121 & 47.6 \\
\hline \multicolumn{3}{|l|}{ Birth order } \\
\hline First & 44 & 17.3 \\
\hline Second & 57 & 22.4 \\
\hline Third & 54 & 21.3 \\
\hline Fourth \& above & 99 & 39.0 \\
\hline \multicolumn{3}{|l|}{ Place of delivery } \\
\hline Home & 223 & 87.8 \\
\hline Health institution & 31 & 12.2 \\
\hline \multicolumn{3}{|c|}{ Migration/movement in the last 12 months } \\
\hline No movement & 172 & 67.7 \\
\hline Once & 64 & 25.2 \\
\hline Twice & 18 & 7.1 \\
\hline
\end{tabular}

place to search for suitable locations for themselves and for their livestock (Table 1).

\section{Exclusive breastfeeding status of children}

One hundred and fifty-four (60.6\%) of the children received breast milk within 1 hour immediately after birth 
Table 2 EBF status of children now aged between 6 and 24 months during the first 6 months of life $(n=254)$ in Hadaleala district, Afar region, northeast Ethiopia

\begin{tabular}{|c|c|c|}
\hline Variables & Frequency & Percent \\
\hline \multicolumn{3}{|l|}{ Breastfed in first hour } \\
\hline Yes & 154 & 60.6 \\
\hline No & 100 & 39.4 \\
\hline \multicolumn{3}{|c|}{ Child breastfed at the time of the survey } \\
\hline Yes & 207 & 81.5 \\
\hline No & 47 & 18.5 \\
\hline \multicolumn{3}{|l|}{ Child feeding status } \\
\hline Not exclusively breastfed & 66 & 26.0 \\
\hline Exclusively breastfed & 188 & 74.0 \\
\hline \multicolumn{3}{|l|}{ Type of supplementary feeds } \\
\hline Cow's or goat's milk & 179 & 70.5 \\
\hline Infant formula/powder milk & 9 & 3.5 \\
\hline Gruel & 59 & 23.2 \\
\hline Adults' food & 7 & 2.8 \\
\hline \multicolumn{3}{|l|}{ Child consumed leftover foods } \\
\hline Yes & 233 & 91.7 \\
\hline No & 21 & 8.3 \\
\hline \multicolumn{3}{|c|}{ Feeding children soon after food preparation } \\
\hline Yes & 187 & 73.6 \\
\hline No & 67 & 26.4 \\
\hline \multicolumn{3}{|c|}{ Serving uncooked food/ unheated milk to children } \\
\hline Yes & 128 & 50.4 \\
\hline No & 126 & 49.6 \\
\hline
\end{tabular}

and the majority ( $n=207,81.5 \%)$ of the children maintained breastfeeding at the time of the survey. From a total of children aged between 6 and 24 months, 188 were fed breast milk exclusively during the first 6 months of age while the rest had started complementary or supplementary foods. The level of EBF practice in the area was therefore found to be $74 \%$ (95\% CI 70\%, 78\%). The common complementary or supplementary food provided to the children was cow or goat milk, which accounted for $70.5 \%(n=179)$. Two hundred thirtythree $(91.7 \%)$ of the children consumed leftover foods while half $(n=128,50.4 \%)$ were given uncooked foods. Nearly three-quarters of the children $(n=187,73.6 \%)$ consumed foods immediately after cooking (Table 2).

\section{Factors associated with breastfeeding status of children}

Migration in the last 12 months, age of mothers, maternal education, occupation of mothers, marital status of mothers, paternal education, place of birth, family size, sex of children, birth order, and being breastfed in first hour were variables which fulfilled the chi-square test assumption and were entered to the univariable binary logistic regression model. Age of mothers, maternal education, paternal education, birth order, breastfed in first hour, place of birth, and migration in the last 12 months were selected for the multivariable binary logistic regression analysis. Finally, migration in the last 12 months, age of mothers, and breastfed in first hour were significantly associated with exclusive breastfeeding status in the multivariable binary logistic regression analysis (Table 3 ).

This study indicated that the mother's age was statistically associated with breastfeeding status of children for the first 6 months of age. The odds of practicing EBF was 8.3 times more likely to be higher amongst mothers aged above 35 years compared with mothers aged between 15 and 24 years (AOR 8.3, 95\% CI 1.7, 40.3). Breastfeeding in the first hour was found to be associated with the practice of EBF. Exclusive breastfeeding was 3.5 times more likely to be higher among mothers who initiated breastfeeding within 1 hour immediately after birth compared with their counterparts (AOR 3.5, 95\% CI 1.8, 6.9). Moreover, displacement or instability was the other variable associated with EBF; EBF was 4.6 times more likely to be higher among children whose parents didn't migrate from place to place searching for suitable locations for themselves and their livestock, compared with families who migrated twice a year (AOR 4.6, 95\% CI 1.5, 14.4). The practice of EBF was also associated with frequency of migration. For instance, the practice of EBF was 4.4 times higher among children whose parents migrated once a year compared with children whose parents moved twice a year (AOR $4.4,95 \%$ CI $1.3,14.8$ ).

\section{Discussion}

This study investigated the exclusive breastfeeding status of children during the first 6 months of life, when aged between 6 and 24 months. The level of EBF practice in the area was found to be $74 \%$ (95\% CI 70, 78\%). The level of EBF reported in this study is consistent with findings of other similar studies conducted in Ethiopia, for instance studies conducted in Kersa district (71.7\%) [7] and in Halaba special district (70.5\%) [9]. EBF in the current study is higher than the 2011 national prevalence (52\%) [4], and the findings of studies conducted in Ankesha Guagusa District (53\%) [24], Bahir Dar District (50.3\%) [18], Dabat district (30.7\%) [25], and Axum (40.9\%) [26]. This may be due to the small population size in the study area and that health extension workers can frequently provide health information and other healthcare services to mothers. Moreover, most of the mothers in the study area spent their time at home, which could increase the mother's time to provide complete care. Other studies have confirmed that work outside the home is a primary barrier to EBF [27, 28].EBF was higher in studies conducted in Egypt (97.7\%) [29], and Ghana (79\%) [30], which might be due to differences in healthcare coverage and accessibility. 
Table 3 Factors associated with EBF status of children now aged between 6 and 24 months, during the first 6 months of age in Hadaleala district, Afar Region, northeast Ethiopia

\begin{tabular}{|c|c|c|c|c|}
\hline \multirow[t]{2}{*}{ Variables } & \multicolumn{2}{|l|}{ Breastfeeding status } & \multirow[t]{2}{*}{$\operatorname{COR}(95 \% \mathrm{Cl})$} & \multirow[t]{2}{*}{ AOR $(95 \% \mathrm{Cl})$} \\
\hline & Exclusively breastfed (in number) & Not exclusively breastfed (in number) & & \\
\hline \multicolumn{5}{|l|}{ Place of birth } \\
\hline Home & 160 & 63 & 1 & \\
\hline Health institution & 28 & 3 & $3.7(1.1,12.5)$ & $0.8(0.2,3.7)$ \\
\hline \multicolumn{5}{|l|}{ Age of mothers in year } \\
\hline $15.0-24.0$ & 56 & 23 & 1 & \\
\hline $25.0-34.0$ & 92 & 39 & $1.0(0.5,1.8)$ & $1.9(0.7,5.7)$ \\
\hline$\geq 35.0$ & 40 & 4 & $4.1(1.3,12.8)$ & $8.3(1.7,40.3)^{* *}$ \\
\hline \multicolumn{5}{|l|}{ Maternal education } \\
\hline No formal education & 157 & 63 & 1 & \\
\hline Formal education & 31 & 3 & $4.1(1.2,14.1)$ & $1.4(0.3,6.3)$ \\
\hline \multicolumn{5}{|l|}{ Paternal education } \\
\hline No formal education & 161 & 65 & 1 & \\
\hline Formal education & 27 & 1 & $10.9(1.5,81.9)$ & $4.9(0.5,44.6)$ \\
\hline \multicolumn{5}{|l|}{ Breastfed in first hour } \\
\hline Yes & 132 & 22 & $4.7(2.6,8.6)$ & $3.5(1.8,6.9)^{* * *}$ \\
\hline No & 56 & 44 & 1 & \\
\hline \multicolumn{5}{|c|}{ Migration during the last year } \\
\hline No movement & 134 & 38 & $7.1(2.5,20.0)$ & $4.6(1.5,14.4)^{*}$ \\
\hline Once a year & 48 & 16 & $6.0(1.9,18.6)$ & $4.4(1.3,14.8)^{*}$ \\
\hline Twice a year & 6 & 12 & 1 & \\
\hline \multicolumn{5}{|l|}{ Birth order } \\
\hline $1 s t$ & 38 & 6 & $2.1(0.8,5.7)$ & $3.5(0.8,15.4)$ \\
\hline 2nd & 39 & 18 & $0.7(0.4,1.5)$ & $1.1(0.4,3.4)$ \\
\hline $3 r d$ & 37 & 17 & $0.7(0.4,1.5)$ & $1.1(0.5,2.7)$ \\
\hline 4th and above & 74 & 25 & 1 & \\
\hline
\end{tabular}

* Statistically significant variables at $p<0.05,{ }^{* *}$ statistically significant variables at $p<0.01,{ }^{* *}$ statistically significant variables at $p<0.001$, the result of Hosmer and Lemshow test was $>0.470$

Of the $24 \%$ of children in this study who had started supplementary or complementary foods, cow or goat milk (70.5\%), gruel (23.2\%), infant formula/powdered milk (3.5\%), and adults' food (2.8\%), were the common types of complementary or supplementary foods. Almost all $(91.7 \%)$ of the children consumed leftover foods and $26.4 \%$ of the mothers didn't provide foods immediately after preparation. Moreover, 50.4\% consumed uncooked foods. These conditions might increase the risks of food borne infections, especially in regions where sanitation conditions are poor. Early intake of unhygienic complementary foods reduces the intake of breast milk and as a consequence, infants receive fewer protective factors.

This study indicated that a mothers' age was associated with the breastfeeding status of children in the first 6 months of life. Older mothers were more likely to practice EBF than the younger mothers. Other similar studies had also reported similar findings [5, 31-34]. Older mothers might have more experience and knowledge of the health importance of exclusive breastfeeding. Moreover, older mothers might have more antenatal and postnatal care, as well greater knowledge about child care.

Similar to other studies [9, 22, 29, 35-40], this study showed that mothers' EBF practice was associated with early or timely breastfeeding inititation. Mothers who initiated breastfeeding immediately after birth were more likely to practice EBF than mothers who did not. This might be due to the fact that mothers who initiated breastfeeding within 1 hour immediately after birth may understand the nutrient, growth, and the immunologic importance of breastfeeding. As a result, mothers could maintain breastfeeding. The World Health Organization (WHO) report also shows that breastfed in first hour increases the likelihood of exclusive breastfeeding for one to 4 months of life, as well as the overall duration of breastfeeding [41]. 
This study also explored whether displacement or instability of households was associated with EBF. Mothers who did not move or migrate from place to place were more likely to practice EBF than mothers who were displaced or migrated. This might be due to the fact that nomadic populations move from place to place to search for more suitable places for their livestock. Most of the livestock give birth when they are in a comfortable place and the nomads intend to give animal milk to the children [42-45]. Furthermore, displaced mothers may not have time to give care for children because they may be very busy to resettle themselves and to search drinking water sources.

\section{Conclusion}

Exclusive breastfeeding was not fully practiced in the study area. Therefore, promotion of infant and young children feeding (IYCF) is needed in the area to strengthen EBF practices. Moreover, attention should be given to the nomadic mothers and child feeding practices should be integrated with the existed health system.

\section{Abbreviations \\ AOR: Adjusted odds ratio; Cl: Confidence interval; COR: Crude odds ratio; EBF: Exclusive breastfeeding; HDS: Health and demographic survey; IQR: Interquartile range; IYCF: Infant and young child feeding; Km: Kilometer; mm: Millimeter; SPSS: Statistical package for social sciences; UNICEF: United Nations Children's Fund; WHO: World Health Organization}

\section{Acknowledgments}

The authors are pleased to acknowledge data collectors, field supervisors, study participants, and others who took part in this study.

\section{Funding}

This study had no any special fund. However, University of Gondar had covered questionnaire printing and data collection fee.

\section{Availability of data and materials}

Data will be made available upon requesting the primary author.

\section{Authors' contributions}

WW developed the study protocol and participated in data collection. ZG analyzed the data and prepared the manuscript. BDB revised the study protocol and the manuscript. All authors read and approved the final manuscript.

\section{Ethics approval and consent to participate}

Ethical clearance was obtained from the Institutional Review Board of the University of Gondar. Hence, the study has no invasive procedures; verbal informed consent was obtained from the mothers. All information collected from each household was treated with complete confidentiality and the data were used only for this research purpose. There were no associated risks due to participation in this research project.

\section{Consent for publication}

This manuscript does not contain any individual person's data.

\section{Competing interests}

The authors declare that they have no competing interests.

\section{Publisher's Note}

Springer Nature remains neutral with regard to jurisdictional claims in published maps and institutional affiliations.

\section{Author details}

'Department of Environmental and Occupational Health and Safety, Institute of Public Health, College of Medicine and Health Sciences, University of Gondar, Gondar, Ethiopia. ${ }^{2}$ Hadaleala District Health Office, Hadaleala District, Northeast Ethiopia, Afar Regional State, Ethiopia.

Received: 19 April 2017 Accepted: 13 August 2017

Published online: 24 August 2017

\section{References}

1. WHO. Infant and young child nutrition: Global strategy on infant and young child feeding Available at http://appswhoint/gb/archive/pdf_files/WHA55/ ea5515pdf?ua=1. Accessed 15 Dec 2016.

2. WHO \& UNICEF. Global Strategy for Infant and Young Child Feeding: A joint WHO/UNICEF statement. Geneva, Switzerland: WHO; 2003. Available at www.who.int/nutrition/publications/gs_infant_feeding_text_eng.pdf. Accessed 22 Jan 20162

3. UNICEF. Breastfeeding. A post-2015 world fit for children. Available at https://www.unicef.org/agenda2030/files/Breastfeeding_2pager_FINAL1_ web.pdf. Accessed 27 Jan 2016.

4. CSA. Ethiopian Demographic and Health Survey - 2011. Central Statistical Agency Addis Ababa. Ethiopia ICF International Calverton, Maryland, USA. 2012. Available at https://dhsprogramcom/pubs/pdf/FR255/FR255pdf. Accessed 28 Jan 2016.

5. Asemahagn MA. Determinants of exclusive breastfeeding practices among mothers in azezo district, northwest Ethiopia. Int Breastfeed J. 2016;11:22.

6. Al-Sahab B, Lanes A, Feldman M, Tamim H. Prevalence and predictors of 6month exclusive breastfeeding among Canadian women: a national survey. BMC Pediatr. 2010;10:20.

7. Egata $G$, Berhane $Y$, Worku A. Predictors of non-exclusive breastfeeding at 6 months among rural mothers in east Ethiopia: a community-based analytical cross-sectional study. Int Breastfeed J. 2013;8:8.

8. Lenja A, Demissie T, Yohannes B, Yohannis M. Determinants of exclusive breastfeeding practice to infants aged less than six months in Offa district, Southern Ethiopia: a cross-sectional study. Int Breastfeed J. 2016;11:32.

9. Sonko A, Worku A. Prevalence and predictors of exclusive breastfeeding for the first six months of life among women in Halaba special woreda, southern nations, nationalities and peoples' region/SNNPR/, Ethiopia: a community based cross-sectional study. Arch Public Health. 2015; 73:53.

10. Venancio SI, Monteiro CA. Individual and contextual determinants of exclusive breast-feeding in São Paulo, Brazil: a multilevel analysis. Public Health Nutr. 2006;9(01):40-6.

11. Baker EJ, Sanei LC, Franklin N. Early initiation of and exclusive breastfeeding in large-scale community-based programmes in Bolivia and Madagascar. J Health Popul Nutr. 2006;24(4):530-9.

12. Lande B, Andersen L, Baerug A, Trygg K, Lund-Larsen K, Veierød M, Bjørneboe G, Aa E. Infant feeding practices and associated factors in the first six months of life: the Norwegian infant nutrition survey. Acta Paediatr. 2003;92(2):152-61.

13. Clifford TJ, Campbell MK, Speechley KN, Gorodzinsky F. Factors influencing full breastfeeding in a southwestern Ontario community: assessments at 1 week and at 6 months postpartum. J Hum Lact. 2006;22(3):292-304.

14. Yang Q, Wen SW, Dubois L, Chen Y, Walker MC, Krewski D. Determinants of breast-feeding and weaning in Alberta, Canada. J Obstet Gynaecol Can. 2004;26(11):975-81.

15. Ethiopia. Hadaleala district Finance and economic development office annual report 2014, by Dawud Haji Alisadik and others, Hadaleala. Ethiopia: Office of finance and economic development Afar Region; 2014.

16. Bogale S. Nutrition Baseline Report, 2014. Available at https:/prime-ethiopia. Org/wp-content/uploads/2015/08/nutrition\%20Baseline\%20Report_GRAD. Pdf. Accesed on Mar 2015.

17. Fewtrell M, Wilson DC, Booth I, Lucas A. Six months of exclusive breast feeding: how good is the evidence? Br Med J. 2011;342:c5955.

18. Seid AM, Yesuf ME, Koye DN. Prevalence of exclusive breastfeeding practices and associated factors among mothers in Bahir Dar city, Northwest Ethiopia: a community based cross-sectional study. Int Breastfeed J. 2013;8:14.

19. Mekuria G, Edris M. Exclusive breastfeeding and associated factors among mothers in Debre Markos, Northwest Ethiopia: a cross-sectional study. Int Breastfeed J. 2015;10:1. 
20. Shifraw T, Worku A, Berhane Y. Factors associated exclusive breastfeeding practices of urban women in Addis Ababa public health centers, Ethiopia: a cross sectional study. Int Breastfeed J. 2015;10:22.

21. Alemayehu T, Haidar J, Habte D. Determinants of exclusive breastfeeding practices in Ethiopia. Ethiop J Health Dev. 2009;23:1.

22. Setegn T, Belachew T, Gerbaba M, Deribe K, Deribew A, Biadgilign S. Factors associated with exclusive breastfeeding practices among mothers in Goba district, south east Ethiopia: a cross-sectional study. Int Breastfeed J. 2012;7:17.

23. Sefene A, Birhanu D, Awoke W, Taye T. Determinants of exclusive breastfeeding practice among mothers of children age less than 6 month in Bahir Dar city administration, Northwest Ethiopia; a community based cross-sectional survey. Sci J Clin Med. 2013;2(6):153-9.

24. Yeneabat T, Belachew T, Haile M. Determinants of cessation of exclusive breastfeeding in Ankesha Guagusa Woreda, Awi zone, Northwest Ethiopia: a cross-sectional study. BMC Pregnancy Childbirth. 2014;14:262.

25. Biks GA, Tariku A, Tessema GA. Effects of antenatal care and institutional delivery on exclusive breastfeeding practice in northwest Ethiopia: a nested case-control study. Int Breastfeed J. 2015;10:30.

26. Alemayehu M, Abreha K, Yebyo H, Zemichael K, Gebremichael H. Factors associated with timely initiation and exclusive breast feeding among mothers of Axum town, northern Ethiopia. Sci J Public Health. 2014;2(5):394-401.

27. Dearden KA, Quan LN, Do M, Marsh DR, Pachón H, Schroeder DG, Lang TT. Work outside the home is the primary barrier to exclusive breastfeeding in rural Viet Nam: insights from mothers who exclusively breastfed and worked. Food Nutr Bull. 2002;23(4_suppl2):99-106.

28. Murtagh L, Moulton AD. Working mothers, breastfeeding, and the law. Am J Public Health. 2011;101(2):217-23.

29. Ghwass MMA, Ahmed D. Prevalence and predictors of 6-month exclusive breastfeeding in a rural area in Egypt. Breastfeed Med. 2011;6(4):191-6.

30. Quinn VJ, Guyon AB, Schubert JW, Stone-Jiménez M, Hainsworth MD, Martin LH. Improving breastfeeding practices on a broad scale at the community level: success stories from Africa and Latin America. J Hum Lact. 2005;21(3):345-54.

31. Jones JR, Kogan MD, Singh GK, Dee DL, Grummer-Strawn LM. Factors associated with exclusive breastfeeding in the United States. Pediatrics. 2011;128(6):1117-25

32. Maonga AR, Mahande MJ, Damian DJ, Msuya SE. Factors affecting exclusive breastfeeding among women in Muheza District Tanga northeastern Tanzania: a mixed method community based study. Matern Child Health J. 2016;20(1):77-87.

33. Dare AA, Joseph $\mathrm{H}$, Femi O. Socio-demographic correlates of Breastfeedling practices among mothers in Kogi state, Nigeria. West Afr J Nurs. 2011;22(1):28-37.

34. Neji Ol, Nkemdilim CC, Ferdinand NF. Factors influencing the practice of exclusive breastfeeding among mothers in tertiary health facility in Calabar, Cross River state, Nigeria. Am J Nurs Sci. 2015:4(1):16-21.

35. Maduforo AN, Ubah NC, Obiakor-Okeke P. The practice of exclusive breastfeeding by lactating women in Owerri metropolis, Imo State, Nigeria. Glob Adv Res J Med MedSci. 2013;2(1):13-9.

36. Häggkvist A-P, Brantsæter AL, Grjibovski AM, Helsing E, Meltzer HM, Haugen M. Prevalence of breast-feeding in the Norwegian mother and child cohort study and health service-related correlates of cessation of full breastfeeding. Public Health Nutr. 2010;13(12):2076-86.

37. Cai X, Wardlaw T, Brown DW. Global trends in exclusive breastfeeding. Int Breastfeed J. 2012;7:12

38. Aidam BA, Perez-Escamilla R, Lartey A, Aidam J. Factors associated with exclusive breastfeeding in Accra, Ghana. Eur J Clin Nutr. 2005;59(6):789-96.

39. MBR DN, MAM R, Franco SC, Issler H, Ferraro AA, SJF G. Exclusive breastfeeding in southern Brazil: prevalence and associated factors. Breastfeed Med. 2010;5(2):79-85.

40. Nkala TE, Msuya SE. Prevalence and predictors of exclusive breastfeeding among women in Kigoma region, Western Tanzania: a community based cross-sectional study. Int Breastfeed J. 2011;6:17.

41. WHO. Early initiation of breastfeeding to promote exclusive breastfeeding. Available at http://www.who.int/elena/titles/early_breastfeeding/en/. Accessed on Jul 2015.

42. Sellen DW. Weaning, complementary feeding, and maternal decision making in a rural east African pastoral population. J Hum Lact. 2001;17(3):233-44.

43. Sellen DW. Infant and young child feeding practices among African pastoralists: the Datoga of Tanzania. J Biosoc Sci. 1998;30(04):481-99.

44. Hussein AK. Breastfeeding and complementary feeding practices in Tanzania. East Afr J Public Health. 2005;2(1):27-31.
45. Xu F, Binns C, Yu P, Bai Y. Determinants of breastfeeding initiation in Xinjiang, PR China, 2003-2004. Acta Paediatr. 2007;96(2):257-60.

\section{Submit your next manuscript to BioMed Central and we will help you at every step:}

- We accept pre-submission inquiries

- Our selector tool helps you to find the most relevant journal

- We provide round the clock customer support

- Convenient online submission

- Thorough peer review

- Inclusion in PubMed and all major indexing services

- Maximum visibility for your research

Submit your manuscript at www.biomedcentral.com/submit
) Biomed Central 